\title{
High-resolution statistical quantification of aeolian dust provenance in East Antarctica over the Last Glacial-Interglacial Transition
}

\author{
AUBRY VANDERSTRAETEN ${ }^{1,2}$, NADINE D MATTIELLI ${ }^{1}$, \\ GOULVEN G LARUELLE ${ }^{1}$, ALOYS BORY ${ }^{2}$, STEFANIA \\ GILI $^{1,3}$, PAOLO GABRIELLI $^{4}$, SYBILLE BOXHO ${ }^{1}$ AND \\ STEEVE BONNEVILLE ${ }^{1}$ \\ ${ }^{1}$ Université Libre de Bruxelles \\ ${ }^{2}$ Université de Lille \\ ${ }^{3}$ Princeton University \\ ${ }^{4}$ The Ohio State University \\ Presenting Author: steeve.bonneville@ulb.be
}

Interactions between the atmosphere and the ocean greatly affect Earth's weather and, climate and contribute to its current global change ${ }^{1}$. To decipher the role of atmospheric circulation modifications in past and present climates, the determination of dust provenance in aeolian deposits is paramount. So far, records of dust provenance are not only scarce but also ambiguous as the geochemical methods used to trace dust (i.e., mainly isotopic fingerprint) fail to constrain mixing processes (during atmospheric transport and deposition). In addition, isotope analysis often requires substantial amounts of dust, which drastically limit the temporal resolution. Here, using an unmixing analysis of Rare Earth Elements patterns from dust collected in Epica Dome-C (EDC), Epica Dronning Maud Land (EDML) ice cores ${ }^{2,3}$ and from a large dataset of potential source areas (PSA) over the Southern Hemisphere, we identify and quantify the sources of dust deposited to East Antarctica over the Last Glacial-Interglacial Transition (33 to $2.5 \mathrm{kyr}$ ). These results provide a reconstruction of dust provenance in deep Antarctic ice cores from multi-decadal to centennial temporal resolution. Overall, our results reveal that, during the Last Glacial Maximum, Patagonia delivered stable dust amount to East Antarctica, contributing to about half of the total dust flux. The remaining dust came from New-Zealand which was previously overlooked as a PSA in previous literature but now appears as the second-most important source of dust to E. Antarctica while Southern Africa had only a minor contribution (Puna-Altiplano and Australia being marginal). The transition towards the Holocene saw a gradual shift: at the LGM termination, both contributions from Patagonia and New Zealand dropped while Southern Africa became the main supplier of dust. Our analysis allows relating the evolution of dust provenance and flux in E. Antarctica to documented climatic transitions within PSA and, at a larger scale, within the Southern Hemisphere. This work has major implications for the reconstruction of atmospheric paleocirculation and paleoclimate.

1- Martínez-Garcia, A. et al. [Nature, 476 (2011), 312-315]

2- Gabrielli P. et al. [Quaternary Science Reviews, 29 (2010), 265-273]

3- Wegner A. et al. [Climate of the Past, 8 (2012), 135-147] 